\title{
CAMPAÑAS EN TELEVISIÓN CONTRA LA VIOLENCIA DE GÉNERO DEL MINISTERIO DE SANIDAD, POLÍTICA SOCIAL E IGUALDAD (2008-2011). ANÁLISIS DE CONTENIDOS PREVIO AL ESTUDIO DE RECEPCIÓN
}

Emma Camarero Calandria1: Universidad de Salamanca. España. emma.camarero@gmail.com

María Marcos Ramos: Universidad de Salamanca. España. mariamarcos@usal.es

\section{RESUMEN}

Este estudio analiza, en su forma, mensaje y contenido las campañas publicitarias realizadas por el Ministerio de Sanidad, Igualdad y Políticas Sociales durante el período 2008-2011. Se trata de analizar, una vez estudiados también datos de carácter cuantitativo y cualitativo, de manera minuciosa las campañas realizadas, analizando qué elementos han sido elegidos por los publicistas para hacer hincapié en el mensaje. Se analizarán, por tanto, los elementos icónicos y textuales, así como los soportes utilizados para lanzar la campaña. También se tendrá en cuenta en qué medida los cambios sociales han influido en los mensajes introducidos en las nuevas campañas. La metodología utilizada para ello es el análisis del discurso, para posteriormente realizar un estudio de percepción de las campañas. El artículo que aquí se presenta es un punto de partida de un estudio posterior donde se analizará la recepción de las campañas realizadas para concienciar sobre esta problemática. Permitirá conocer en profundidad las diferentes campañas para, posteriormente, una vez conocidos los elementos que se han tenido en cuenta para su creación, analizarlos en profundidad de cara a estudiar la recepción de las campañas en los ciudadanos.

PALABRAS CLAVE: Violencia de género - Mujer - Televisión - Campaña publicitaria - Investigación

\footnotetext{
${ }^{1}$ Autor correspondiente:

Emma Camarero Calandria: Profesora Ayudante Doctora de Comunicación Audiovisual de la Universidad de Salamanca. España.

Correo: emma.camarero@gmail.com
} 


\title{
ANALYSIS OF GENDER VIOLENCE AWARENESS CAMPAIGNS PROMOTED BY THE MINISTRY OF HEALTH, DENDER AND SOCIAL POLICIES (2008-2011) SUMMARY
}

\begin{abstract}
This article analyzes the message, the form and contents of campaigns about gender violence awareness promoted by the Spanish Ministry of Health, Gender and Social Policies during the period 2008-2011. The research also has the purpose of studying the data collected in a quantitative and qualitative sense, determining the elements selected by the ads screenwriters to emphasize the message. Iconic and text elements will be studied, as the media chosen for the development of the campaign. Social changes and their influence over the update of the consecutive awareness campaigns are considered as well. The elected method of working it was the previous discourse analysis and further study of the campaign perception.
\end{abstract}

KEY WORDS: Gender violence - Women - Television - Advertising campaign Research

\section{INTRODUCCIÓN}

La Violencia de Género es un desgraciado fenómeno social que se da en mayor o menor medida y frecuencia en todas las sociedades del mundo. El papel absolutamente secundario cuando no marginal de la mujer en gran parte del mundo agudiza esta situación. El grado de desarrollo de cada sociedad, el rol alcanzado por la mujer respecto al hombre, los planes educativos y la fluctuación de este fenómeno son factores que entre otros muchos obligan a variar los contenidos y mensajes de las campañas contra la violencia de género, y más aún cuando hablamos de campañas enfocadas al medio televisivo.

\section{METODOLOGÍA}

El objetivo de este análisis es profundizar sobre los elementos que configuran, a nivel audiovisual, lingüístico y simbólico el lenguaje de estas campañas, si el mismo se adecua a las prioridades que han establecido los organismos e instituciones que las encargan, y sobre todo, si medios, recursos y mensaje realmente logran alcanzar los objetivos prioritarios, esencialmente, la sensibilización social a través del medio televisivo respecto a este problema, sensibilización que debería suponer la disminución paulatina del número de víctimas de la violencia de género. 


\section{ANÁLISIS Y DISCUSIÓN}

Es muy significativo el hecho de que hasta finales de los 90, los asesinatos cometidos cuya causa era la violencia de género, raramente tenían una cobertura comunicacional a gran escala. Seguían siendo denominados literalmente "asuntos de marido y mujer", "violencia doméstica" por gran parte de la población pero también por los medios de comunicación, aunque empezaba a vislumbrarse un cambio de mentalidades que hizo posible la creación de las campañas publicitarias televisivas.

En 1997 el Parlamento de Europa aprobó una resolución a favor de una campaña contra la violencia de género con el mensaje de “Tolerancia cero contra la Violencia de Género". El objetivo principal entonces era informar sobre las manifestaciones, efectos y amplitud de la violencia contra las mujeres y la infancia y demostrar la necesidad de una legislación efectiva. Después de la iniciativa del Parlamento de Europa, y ya con la aprobación en España en 2004 de una Ley Integral, hace mucho que se asumió que era indispensable tratar de posicionar a la sociedad por medio de campañas entre otros instrumentos de comunicación. Hoy, todas las comunidades autónomas en España han legislado también para luchar contra la violencia de género, además de otras instituciones públicas y privadas, que utilizan las campañas en televisión como herramientas habitual de lucha contra la violencia de género.

En este proceso de concienciación a través de campañas televisivas, debía de ser esencial la elección de un lenguaje y un mensaje determinado cuyo objetivo final fuese sensibilizar a la mayoría de la población española. Un lenguaje por un lado alejado de los objetivos más generales de la publicidad en cuanto a "vender", pero por otro lado, inmerso en ella en lo que a "convencer" se refiere.

La iconización forma parte de las estrategias generales de la persuasión, pero aun asumiendo sus valiosas aportaciones a este trabajo, se pretende además "situar el fenómeno de la textualidad publicitaria en el plano perceptivo-comunicativo" (Vellón, 2007: 31), ya que contextualiza metodológicamente las líneas interpretativas de este estudio.

Para la realización de este análisis, hemos utilizado la siguiente metodología:

- Exhaustiva búsqueda documental, videográfica y bibliográfica relativa a las campañas contra la violencia de género para televisión con tres niveles de aplicación: autonómico, nacional e internacional.

- Análisis de las campañas concretas a las que se refiere este estudio, las realizadas por el Ministerio de Igualdad entre 2008 y 2011, desde su puesta en marcha hasta su finalización. Análisis de la documentación relativa a estas campañas, tanto en su realización audiovisual como en sus contenidos, objetivos, ámbito de aplicación, temporalidad y recursos materiales.

- Estudio de los datos cuantitativos y cualitativos relativos a la violencia de género en España en el período de vigencia de cada una de las campañas, así como datos estadísticos relacionados con la aplicación y puesta en marcha de las campañas en televisión. Principalmente se han analizado cifras oficiales de carácter estadístico 
facilitadas entre otros organismos, por el Ministerio de Sanidad, Igualdad y Políticas Sociales, el Observatorio de la Mujer o en Centro de Investigaciones Sociológicas (CIS).

- $\quad$ Estudio comparativo de los datos obtenidos para establecer en qué medida las campañas analizadas han podido contribuir a alcanzar los objetivos marcados por el Ministerio en su lucha contra la violencia de género.

\subsection{Contenido: Análisis de las campañas contra la violencia de género en televisión del Ministerio de Igualdad de España (2008-2011).}

En sus inicios, la cara de la mayoría de las campañas ha sido la de una mujer con las huellas de la violencia, una imagen que incidía sobre todo en la idea de que éste era un problema que sólo afectaba a las mujeres. El lenguaje textual también estaba al servicio de este objetivo. En su momento, fue importante destacar esta situación ante la invisibilidad social de esta violencia y ante el desconocimiento de su realidad. Se considera imprescindible, en cualquier caso, "realizar un acercamiento desde la perspectiva estadística que permita efectuar un seguimiento de la magnitud y la evolución del fenómeno al menos en algunas de sus manifestaciones" (II Informe Anual sobre Violencia de Género, 2009: 3). No es una violencia en abstracto ni genérica, afecta a la mujer, pero también a hijos, familia, entorno social, $\mathrm{y}$, evidentemente, no debe tolerarse la violencia que ejerce el maltratador. Las últimas campañas precisamente inciden en que quien debe recibir toda la crítica y reprobación social es el que ejerce la violencia.

Al eslogan, que es por definición la frase más destacada de la campaña publicitaria, además de brevedad, se le exige ciertas cualidades de memorización y una total especificidad. A veces es una síntesis -formal o de contenido-, del texto que la acompaña. Es las campañas del Ministerio de Igualdad, los eslóganes elegidos son realmente los que deciden el resto del lenguaje de cada spot, son la consecuencia de los hechos narrados, en definitiva la ansiada pero tan sólo teórica solución al problema.

En cuanto a los elementos analizados desde una metodología cualitativa, la iconización forma parte de las estrategias generales de la persuasión, pero aun asumiendo sus valiosas aportaciones a este trabajo, se pretende además "situar el fenómeno de la textualidad publicitaria en el plano perceptivo-comunicativo" (Vellón, 2007: 31), ya que contextualiza metodológicamente las líneas interpretativas de este estudio.

Se han analizado las campañas en televisión contra la violencia de género realizadas por el Ministerio de Igualdad (actualmente Ministerio de Sanidad, Igualdad y Políticas Sociales) durante los años 2008, 2009, 2010 y 2011. Podríamos decir que la de 2008 es la primera campaña global contra la violencia de género en España. A estas actuaciones ministeriales habrían de unirse las realizadas por gobiernos autonómicos, ayuntamientos e instituciones, valorables en su conjunto en la lucha contra la violencia de género. El lenguaje publicitario, el mensaje, suele coincidir plenamente con las campañas llevadas a cabo por el Ministerio cuando no lo complementan. 
Las campañas contra los malos tratos pueden adoptar diferentes formas en su propósito de prevenir, anticipar, combatir y, finalmente, erradicar la violencia contra las mujeres. En este objetivo múltiple se encuentra la motivación central que guía la idea de hacer campañas de prevención contra este tipo de violencia. Las campañas responden a un determinado análisis del problema de los malos tratos e intentan contrarrestar algunas de las causas que los posibilitan o de neutralizar algunos de los obstáculos que se oponen a su erradicación (Molina González, 2005: 11).

Las campañas televisivas de prevención de la violencia contra las mujeres son una práctica común, pero es difícil establecer la relación entre éstas, el incremento de la sensibilización y la disminución de los índices de violencia. Del tal modo que sólo es posible detectar esta relación mediante la evaluación de las campañas llevadas a cabo y una interpretación a priori de la influencia que la televisión tienen en la evolución de las actitudes que la población manifiesta en un periodo temporal dado.

Aunque en la actualidad cada vez más campañas son evaluadas sistemáticamente, esta estrategia aún no se ha convertido en una práctica habitual. En general se analizan los datos mensuales y anuales de violencia de género, pero rara vez se reflexiona y analiza la eficacia de las campañas televisivas en el mayor o menor éxito en su erradicación como fenómeno social negativo. Evidentemente, la capacidad de concienciación y sensibilización de las campañas en televisión es limitada debido a una serie de causas y circunstancias sociales que fluctúan en el tiempo, cambian y hacen de este fenómeno, un problema con numerosas vertientes causales y consecuentes.

La enorme complejidad de la violencia de género y sus orígenes dificulta enormemente su estudio y la individualización de sus causas. Por ello los primeros resultados de este estudio apuntan a que aún no se ha conseguido encontrar la vía correcta en la sensibilización a través del uso de campañas publicitarias en televisión.

\subsection{Campaña 2008: "Ante el maltratador, tolerancia cero".}

En 2008 - cuatro años después de la aprobación de la Ley Integral para la lucha contra la Violencia de Género-, aparece en España el primer plan de comunicación sostenido en el tiempo que incluían campañas de sensibilización en Televisión, y que buscaba la complicidad de toda la sociedad para erradicar la violencia contra las mujeres, informar a las víctimas de sus derechos y de los instrumentos previstos para su protección, y conseguir un rechazo social hacia los maltratadores.

La novedad de esta campaña radica en buscar la connivencia de los hombres en el rechazo contra la violencia de género y especialmente contra los maltratadores, mostrar las consecuencias de la violencia en los menores y la prevención de la violencia en mujeres, con spots protagonizados por españolas e inmigrantes.

Si tenemos en cuenta que el eslogan de esta campaña, "Contra el maltratador, tolerancia cero", había sido creado once años antes en el Parlamento Europeo, podemos entender que el estadio de desarrollo de la conciencia colectiva española 
había necesitado de tiempo para llegar a un grado de madurez suficiente como para aceptar este tipo de mensajes textuales.

El spot de los hombres utiliza un lenguaje que evidencia el rechazo del resto de los hombres al agresor - "cada vez que maltratas a una mujer, dejas de ser un hombre"-, mientras que el spot de las mujeres destaca a mujeres con la voz y la iniciativa de decir no al violento en nombre de toda la sociedad, "visto como quiero, no tengo miedo, no se te ocurra levantarme la mano jamás". El spot incluye la presencia de mujeres inmigrantes por la necesidad de que los mensajes de estas campañas empiecen a penetrar con urgencia en la comunidad inmigrante.

Esta campaña pretende, además, que los menores sean los protagonistas de un futuro sin violencia de género. En este caso, junto al eslogan general de la campaña aparece otro de profundo significado, "No lo hagas por nosotros, hazlo por nosotros". Se trata de incidir en uno de los aspectos de este drama -los hijos-, que tanto para la madre como para el presunto maltratador, muchas veces el propio padre, más pueden hacerles cambiar en sus actitudes de silencio y de violencia respectivamente.

Esta campaña utiliza un lenguaje directo, dirigido al hombre o la mujer como simbólicos interlocutores, y enunciado de forma imperativa. Pero a pesar de ser la primera campaña global realizada en España, no significó un avance en la lucha contra la violencia de género. 2008 ha sido el año con mayor número de muertes por violencia de género de la última década. Dado el fracaso del eslogan y de la propia campaña de concienciación, desde el Ministerio de Igualdad se decidió empezar a trabajar en otra dirección, utilizando un lenguaje más conciliador y menos agresivo en campañas posteriores.

\subsection{Campaña 2009: "Ante el maltrato, todas y todos a una".}

La campaña institucional del Ministerio en 2009 vuelve a utilizar parte del eslogan de la anterior, "ante el maltratador...", pero en cambio, la segunda parte del lema conlleva un mensaje mucho más conciliador que en 2008, "todos y todas a una". El lenguaje textual utilizado mucho más escueto, transmite la situación de temor y miedo en la que viven las mujeres víctimas de violencia de género con una llamada a la sociedad para que actúe frente a los malos tratos. Así, la campaña utiliza el mensaje "Ya no tengo miedo". Un mensaje en positivo que es la respuesta de las mujeres al sentir que toda la sociedad está detrás de ellas para protegerlas y apoyarlas.

Marca una ruptura más que una evolución con la campaña de 2008. Frente al imperativo, a la imposición, a colocar a la mujer ante la necesidad de tomar una decisión y de enfrentarse a sus propios miedos de forma individual, en 2009 el mensaje es que no están solas para tomar esas decisiones, sino que toda la sociedad va a ayudarlas.

Este cambio de lenguaje es producto en gran medida de un dato estadístico de 2008; solo el $23,7 \%$ de las víctimas había denunciado malos tratos, y de ellas el 2,6\% las 
habían retirado. Dada la dificultad para convencer a muchas mujeres de que denuncie, el eslogan de esta campaña busca la complicidad de la sociedad para ayudarla.

Esta campaña publicitaria junto a otra serie de medidas puestas en marcha en 2009 en la lucha contra la violencia de género, y probablemente una serie de circunstancias de carácter coyuntural, consiguieron que ese año la tasa de víctimas mortales por violencia de género fuera la más baja de los últimos 20 años pasando de 76 a 55 asesinatos, un $27,6 \%$ menos que en 2008 .

\subsection{Campaña 2010: "Saca tarjeta roja al maltratador".}

Con los datos positivos relativos a la lucha contra la violencia de género del 2009, en 2010 se crea la más ambiciosa y amplia campaña realizada hasta el momento por el Ministerio. Si en 2008 el presupuesto de estas campañas ascendió a 4,3 millones de euros, para el 2010 en Ministerio de Igualdad destinará casi el doble, 8,5 millones, en una campaña que contará con la presencia de personajes públicos como protagonistas. El símbolo-idea que preside la campaña en 2010 es la tarjeta roja como reflejo del rechazo social contra el maltratador y por ser un gesto y un símbolo conocido de forma general, y particularmente en el ámbito deportivo: quien no juega limpio, queda fuera de la sociedad. Cada gesto que muestre la Tarjeta Roja reflejará el rechazo a los maltratadores y, al mismo tiempo, el apoyo a las mujeres que sufren su violencia.

No puede negarse que existe un grado de oportunismo en este eslogan, ya que el argot futbolístico está de plena actualidad ya que en 2010 tiene lugar el Mundial de Fútbol de Sudáfrica con la selección española como una de las favoritas. Esta campaña, al margen de la utilización de un recurso lingüístico simplista como es esta expresión popular en su mensaje, producto quizás de un ingenuo optimismo, de una cierta banalización del lenguaje vinculada al éxito de la campaña 2009, es en cambio, la más compleja de todas las creadas hasta ahora.

La campaña original para televisión y cine está compuesta por ocho spots de entre 20 y 120 segundos. El objetivo es generar un movimiento social, de forma que cada uno de nosotros, a título personal, acoja el símbolo de la Tarjeta Roja al maltratador y lo haga suyo. Para ello se crea una página web www.sacatarjetaroja.es en la que quien lo desee puede descargar su propia tarjeta roja, hacerse una foto con ella y subirla a la misma web.

El lenguaje utilizado en esta campaña es una simbiosis en el plano simbólico del mensaje de las dos campañas anteriores. De hecho, la simplicidad de la imagen utilizada, actores contra fondos oscuros débilmente iluminados, otorga al lenguaje textual un valor esencial en la transmisión del mensaje de la campaña. Alguno de los spots - especialmente los realizados para el medio televisivo-, que cuentan con la participación de personajes famosos, utilizan de nuevo el lenguaje imperativo, los hombres en su mayoría con connotaciones negativas dirigiéndose a la mujer, "tú es que no sabes hacer nada bien, me vas a llevar a la ruina, ¿no sabes más que gastar?" la mujer no maltratada dirigiéndose al maltratador "claro que puedes pegarle, claro que 
gritas más fuerte, claro que llama a escondidas", para terminar con un mensaje proclamado por hombres a otros hombres, "quien maltrata a una mujer no tiene sitio en nuestra sociedad. Plántate, sácale tarjeta roja al maltratador".

Los spots de más larga duración representan personajes que pretenden ser reflejo de muchas personas que de forma cercana, pero indirecta y con sentimiento de culpa han vivido el drama del maltrato: un hijo, un hermano, un amigo. El lenguaje utilizado en este caso busca, a través de la utilización de frases muy habituales, generar conciencia sobre la necesidad de actuar ante el maltrato - "él siempre hablaba mal de ella", "yo se lo dije, que se pasaba un huevo", "es duro porque es tu padre y le odias", "son cosas de ellos, de mi hermano, decía yo", "no piensas tampoco que va a llegar tan lejos", " yo la vi justo el día antes de que la matara", "si no hubiera estado sola", "tenía que haber ido a por él, a la policía, yo qué sé" -.

El final del spot, representa a esos mismos personajes con un papel activo en cada historia de maltrato, "estoy harto de escuchar que tú no querías. Si golpeas, amenazas o insultas, no cuentes con mi silencio porque voy a denunciarte". De nuevo un lenguaje imperativo, de enfrentamiento al agresor, pero esta vez, a diferencia de la campaña 2008, no es la mujer la que se enfrenta directamente, son los hombres, iguales ante el maltratador, los que toman la iniciativa de la sociedad contra la violencia de género.

Pero a pesar de la enorme cantidad de medios, canales y recursos sin precedentes en España al servicio de esta campaña y en general, en la lucha contra la violencia de género, ateniéndonos a las cifras de víctimas mortales, no parece que se hayan conseguido los objetivos marcados. En 2010 fueron asesinadas 73 mujeres, lo que supone un aumento del 23,3\% con respecto a 2009.

\subsection{Campaña 2011: “No te saltes las señales, elige vivir".}

Esta campaña fue presentada en septiembre de 2011. De nuevo, un mensaje dirigido directamente a las mujeres, esta vez buceando en el origen del problema, las señales de un posible maltrato futuro. La prevención a través de la sensibilización constituye una de las claves en la lucha contra la violencia de género y esta campaña busca de nuevo la complicidad de toda la sociedad para erradicar la violencia contra las mujeres, informar a las víctimas de sus derechos y de los instrumentos previstos para su protección, y conseguir el rechazo social hacia los maltratadores. La campaña advierte ante este tipo de señales a través de un mensaje dirigido a las mujeres víctimas y también a sus entornos.

La campaña tiene un presupuesto de algo más de 4,5 millones de euros, -supone una reducción bastante considerable de fondos con respecto a 2010-, para la planificación de medios y una duración continuada y multifocal durante todo un año. Se emitirá en todas las cadenas de televisión y radios nacionales y las principales autonómicas, cada una en su lengua específica. Además, se programará en las emisoras de radiofórmula, lo que es una novedad. 
No presenta casi novedades desde el punto de vista del tratamiento del mensaje. Sigue obviándose la violencia explícita para mostrar las consecuencias y repercusiones de la misma en nuestro entorno. Aunque hay referencias al maltratador, esta vez no es el objetivo del mensaje.

Los datos estadísticos de 2011 apuntan a una reducción del número de víctimas de violencia de género del $16 \%$ con respecto a 2010, pasando de 73 a 61 mujeres asesinadas a manos de sus parejas o ex parejas. A la espera de poder comparar estos datos con los del 2012, vuelve a plantearse la violencia de género como un fenómeno fluctuante. Las causas -sociales, económicas, culturales, etc.-, que provocan su aumento o disminución son por ello muy variadas y complejas, y por tanto muy difíciles de individualizar y aislar para poder ser erradicadas con éxito de la sociedad.

\section{CONCLUSIONES}

Para conocer la eficacia de estas campañas es necesario un control exhaustivo de su grado de penetración en la población. El control más operativo que puede realizarse consiste en evaluar la penetración de la campaña entre la población objetivo al finalizar la misma. Si en dicho control se efectúa un seguimiento de la penetración, es posible que se pueda determinar el nivel de presión a partir del cual ya no se produce un incremento, lo que permite adoptar decisiones en campañas futuras sobre la duración de las mismas y los niveles de inversión más convenientes.

La medición de la eficacia de las campañas, en una primera etapa conlleva un control del tratamiento de diferentes entidades y personas que actúan a lo largo del proceso y deben colaborar activamente para demostrar la calidad y la utilidad de las campañas difundidas. La segunda etapa sirve para evaluar los resultados obtenidos en los cambios de actitudes, con los que se puede establecer hasta qué punto la campaña ha permitido modificar las percepciones de las personas en relación a este problema. Por último, existe un tercer nivel en el que se miden los cambios en el comportamiento de las personas generados a raíz de la campaña.

El análisis realizado para valorar las campañas contra la violencia de género realizadas por el Ministerio de Igualdad en el período establecido, así como la eficacia del lenguaje y el mensaje utilizado, apuntan a que son precisamente los spots televisivos las herramientas más eficaces en la concienciación contra la violencia de género, en cuanto que son éstos los que mayor proyección y calado social tienen. Según la encuesta del CIS sobre Percepción de la Violencia contra la Mujer en España (Informe Ejecutivo del III Informe Anual del Observatorio Estatal de Violencia sobre la Mujer, 2010: 10), el 70,8\% de la población afirma conocer la información relativa a violencia de género a través de la televisión. Se trata de un aplastante dominio del medio televisivo sobre el resto de los medios de comunicación de masas. Si a este dato unimos el que sea la televisión también para el 18,9\% de la población el segundo medio de comunicación del que procede la información sobre violencia de género, arroja una cifra global del $89,7 \%$ de la sociedad española que conoce la violencia de género a través del medio televisivo. Ello incluye no solo las campañas de 
concienciación y sensibilización sobre este problema. Sino también noticias y reportajes sobre la violencia contra la mujer.

A partir de 2008, y coincidiendo con el momento en que socialmente la violencia machista sufría un repunte en la percepción del problema por parte de la población, se aumentan exponencialmente los recursos y medios al servicio de estas campañas de sensibilización televisivas. A pesar de ello, la mayoría de la población opina que éstas no determinan su estado de opinión, en concreto un 58,3\% (Informe Ejecutivo, 2010: 10).

Analizados estos datos, se obtienen los siguientes resultados:

- La mayoría de la población no considera a las campañas en televisión como un elemento que varíe su forma de pensar sobre este tema $(58,3 \%)$.

- La violencia de género es considerada tan solo por el 2,7\% de la población como uno de los tres problemas más graves de España (dato de la encuestas del CIS de diciembre de 2009).

- El aumento del número de víctimas durante 2010 en más de un 23\% respecto a 2009, obliga a preguntarse hasta qué punto los medios y recursos a disposición de estas campañas justifican la teórica ineficacia de las mismas.

Sería absurdo pensar que estas campañas son la panacea al problema de la violencia de género, o la única herramienta al servicio de su erradicación. Pero el hecho de ser el elemento con mayor impacto social y mediático, aquel que se hace más visible para la población, debería obligar a los responsables de las mismas a crearlas bajo rigurosos criterios, aparcando modas o formatos televisivos y publicitarios. Su realización y puesta en marcha debería basarse esencialmente en el estudio pormenorizado de la evolución del fenómeno de la violencia de género desde la puesta en marcha de la anterior campaña, con el objetivo de valorar su eficacia y variar el mensaje y la forma, y si se han producido variaciones significativas en este fenómeno violento que así lo exige para luchar contra él con eficacia. La valoración y estudio de la experiencia de otras campañas en diferentes ámbitos de aplicación, ya sea a nivel nacional o internacional sería una medida a tener en cuenta en la creación de nuevas estrategias comunicativas.

La violencia de género es un fenómeno que fluctúa, cambia, aparecen nuevos condicionantes, desaparecen otros; la campaña en televisión debe ser lo suficientemente flexible para poder variar sus objetivos y por ello sus contenidos y mensajes si la situación lo hace necesario. Si dicha campaña pierde validez o importancia, por la causa que sea, las instituciones deberían ser capaces de reaccionar y actualizarla, o realizar una nueva campaña.

A la vista de la nada esperanzadora evolución de las cifras de víctimas entre 2008 y 2010, así como la falta de penetración de las campañas de sensibilización en la población española, llevan a la conclusión de que en general las políticas para erradicar la violencia contra la mujer, y en concreto las campañas de sensibilización en televisión, a pesar de su potencial mediático, no han sido en absoluto eficaces. El 
aumento del presupuesto destinado a las mismas, la realización de éstas por directores de prestigio y la participación de personalidades en el mensaje no han calado de momento en la sociedad española.

Las campañas en televisión no deberían dar la espalda a la sociedad. A veces las instituciones piensan o quieren pensar que la sociedad en la que vivimos se halla en un estadio de progreso social más avanzado del que en realidad se encuentra. Especialmente en la denuncia al agresor y en provocar su aislamiento social - en 2010, solo 22 de las 73 víctimas mortales denunciaron, y de ellas 4 la retiraron posteriormente-, las campañas y por ende el lenguaje utilizado en ellas no son aún -al menos en España-, lo suficientemente eficaces ni han logrado un nivel de penetración adecuado. Ninguna campaña contra la violencia de género tiene sentido, los mensajes carecen de credibilidad si desde los organismos públicos competentes no se articulan medidas que den respuesta inmediata y protección a las víctimas de violencia de género.

\section{IMÁGENES Y GRÁFICOS}

Ilustración 1. Imagen corporativa de la Campaña 2008
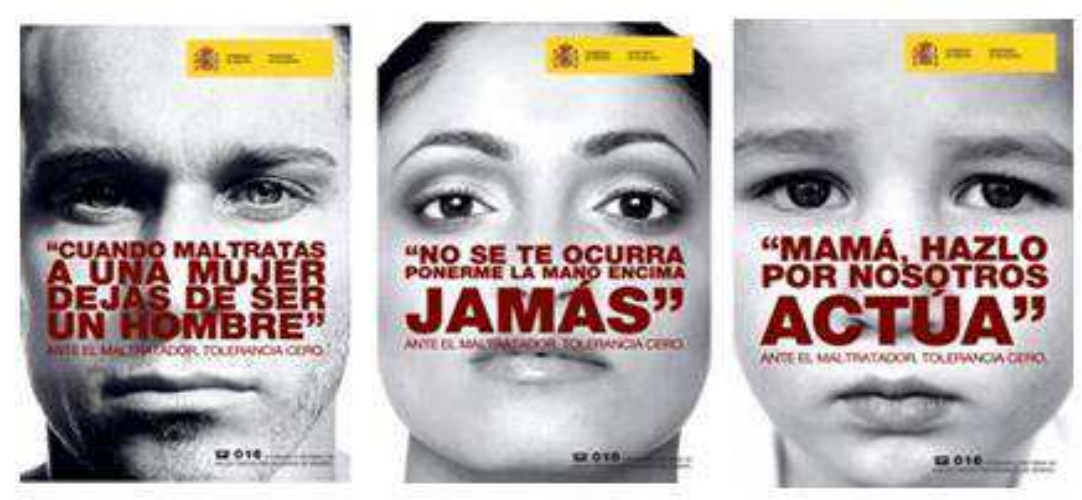

Ilustración 2. Imagen corporativa de la Campaña 2009
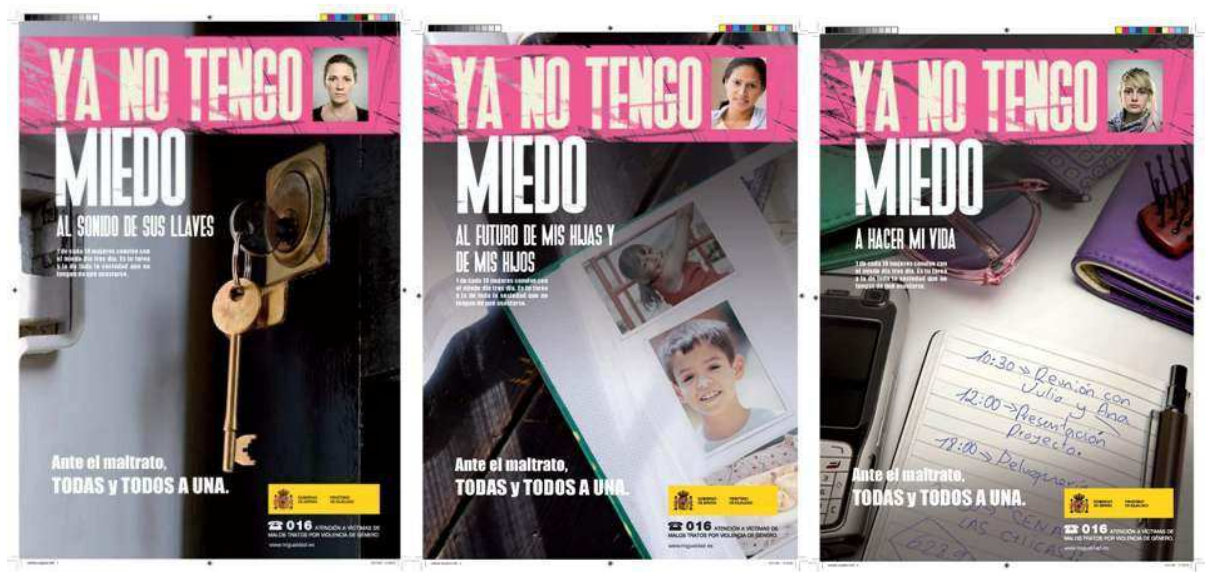
Ilustración 3. Imagen corporativa de la Campaña 2010

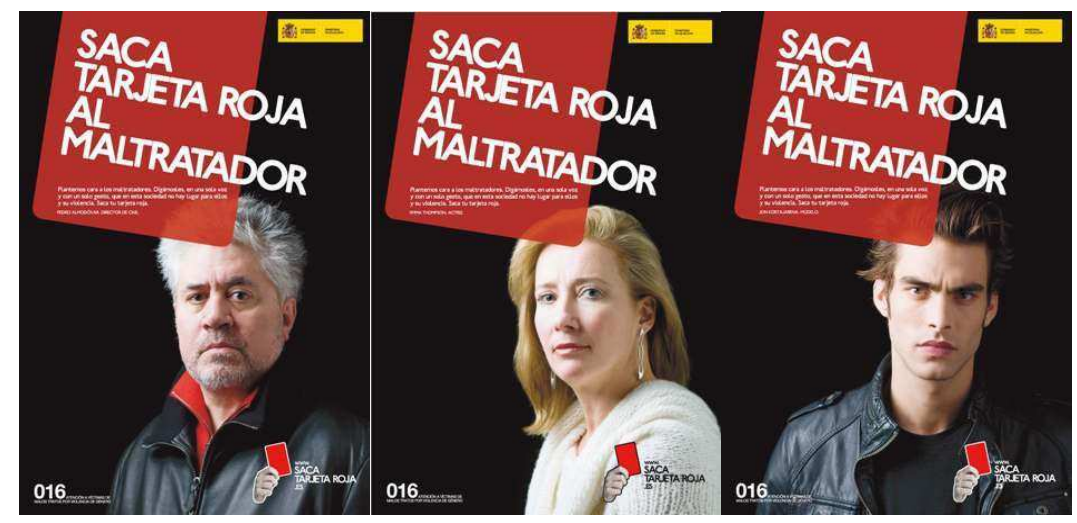

Ilustración 4. Imagen corporativa de la Campaña 2011

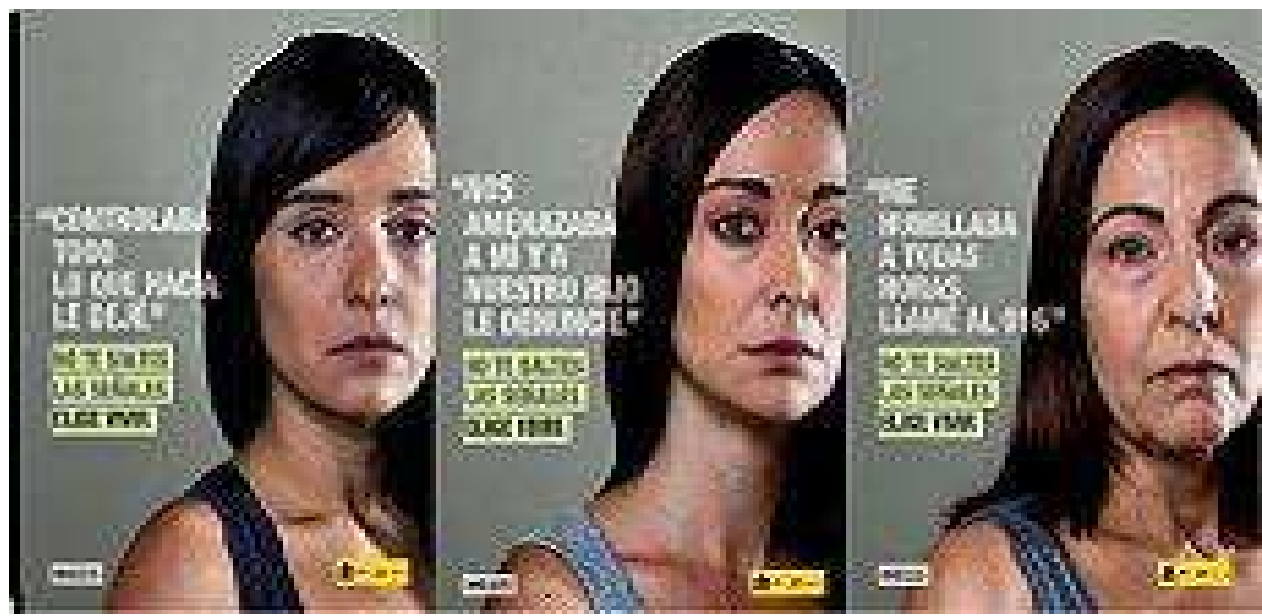

\section{REFERENCIAS}

García, M. (2000). Las claves de la publicidad. Madrid: ESIC

González, J. A. (1996). Teoría general de la publicidad. Madrid: FCE

López, P. (dir.) (2005). Representación de Género en los Informativos de Radio y Televisión. Madrid, Instituto Oficial de Radio y Televisión. Consulta 21 de Noviembre del 2010 (http://www.rtve.es/oficial/iortv/Dossier\%20MUJER\%20Y\%20VIOLENCIA.pdf)

Martinel, E. (1979). “Lingüística y Publicidad”. En Revista española de lingüística, Año no 9, Fasc. 1, pp. 173-190.

Molina, A. (dir.) (2005). Análisis de las campañas publicitarias de prevención de la violencia contra la mujer en España (2005). Valencia. Consulta el 20 de Diciembre del 2011. 
(http://www.valencia.es/mujer/mujer.nsf/0/02786D44FC3CC715C1257404002C24B A/\$FILE/17894744.pdf?OpenElement\&=lang=1)

Roman, K. y Maas, J. (1995). El nuevo como anunciar. Madrid: Grupo Control.

Romero, M. V. y Betés, K. 2005. Lenguaje publicitario: la seducción permanente. Barcelona: Ariel Comunicación.

Vellón, J. (2007). Estrategias lingüísticas de los textos publicitarios. Barcelona: OUC.

Datos estadísticos relativos a violencia de género en España. Consulta 23 de Enero del 2011.

(http:/ / www.migualdad.es/ss/Satellitec=MIGU_Multimedia_FP\&cid=119304988684

8\&language $=$ cas_ES\&page $=1193049890202 \&$ pagename $=$ MinisterioIgualdad $/$ MIGU_M ultmedia_FP/MIGU_listadoSubcategoria)

\subsection{Vídeos.}

Vídeos Campañas contra la Violencia de Género 2008. Consulta 12 de Enero del 2011 (http:/ / www.migualdad.es/ss/Satellite?c=MIGU_Campania_FA\&cid=1193049832542 \&pagename=MinisterioIgualdad/MIGU_Campania_FA/MIGU_campaniaGenerica)

Vídeos Campaña contra la Violencia de Género 2009. Consulta 12 de Enero del 2011 (http:/ / www.migualdad.es/ss/Satellite?c=MIGU_Campania_FA\&cid=1244647392475 \&language $=$ cas_ES\&pageid=1193049831625\&pagename=MinisterioIgualdad $/$ MIGU_ Campania_FA/MIGU_campaniaGenerica)

Vídeos Campaña contra la Violencia de Género 2010. Consulta 12 de Enero del 2011 (http:/ / 213.27.203.194/ss/Satellite?c=MIGU_Campania_FA\&cid=1244647754921\&lan guage $=$ cas_ES\&pageid $=1193049831625 \&$ pagename $=$ MinisterioIgualdad $/$ MIGU_Camp ania_FA/MIGU_campaniaGenerica)

Vídeos Campaña contra la Violencia de Género 2011. Consulta 20 de Diciembre del 2011 (http:/ / www.seigualdad.gob.es/secretaria/acciones/campanas/eligeVivir.htm)

\subsection{Informes.}

I Informe Anual del Observatorio Estatal sobre Violencia contra la Mujer (2007). Ministerio de Igualdad Social de España. Consulta 12 de Enero del 2011. (www.migualdad.es)

II Informe Anual del Observatorio Estatal sobre Violencia contra la Mujer (2009). Ministerio de Igualdad Social de España. Consulta 12 de Enero del 2011. (www.migualdad.es)

III Informe Anual del Observatorio Estatal sobre Violencia contra la Mujer. Informe Ejecutivo (2010). Ministerio de Igualdad Social de España. Consulta 12 de Enero del 
2011(http:// www.migualdad.es/ss/Satellite?blobcol=urldata\&blobheader=applicatio $\underline{\mathrm{n} / \text { pdf\&blobheadername1=Content- }}$

disposition\&blobheadervalue1=inline\&blobkey $=$ id\&blobtable $=$ MungoBlobs\&blobwhe $\underline{\mathrm{re}=1244653592435 \& \text { ssbinary }=\text { true) }}$

IV Informe Anual del Observatorio Estatal sobre Violencia contra la Mujer. Informe Ejecutivo (2011). Ministerio de Igualdad Social de España. Consulta 20 de Diciembre del 2011 (http:/ / www.seigualdad.gob.es/secretaria/cifrasInformes/infIgualdad.htm)

\section{Emma Camarero Calandria}

Doctora en Historia del Arte y licenciada en Geografía e Historia. Desde 2007 profesora de Comunicación Audiovisual y Publicidad en la Universidad de Salamanca. Desde 1995 su labor profesional ha estado vinculada al mundo de la comunicación audiovisual e institucional, trabajando para Canal Sur TV, La Agencia de Noticias Reuters en Roma, Konic Audiovisuales y Castilla La Mancha TV. Su campo de investigación está centrando en los Géneros Audiovisuales -especialmente en el campo del documental y reportaje de investigación, así como las campañas contra la violencia de género en TV-, y la Comunicación Audiovisual corporativa e institucional. Ha dirigido el proyecto preliminar de gestión y puesta en marcha de la televisión de la Universidad de Salamanca.

\section{María Marcos Ramos}

Licenciada en Comunicación Audiovisual por la Universidad del País Vasco y doctoranda de Comunicación Audiovisual en la Universidad de Salamanca, donde se encuentra realizando su tesis doctoral. Ha realizado trabajos de investigación sobre lenguaje cinematográfico, alfabetización mediática y TIC's en revistas y monografías científicas. Sus líneas de investigación actuales son la alfabetización mediática, la ficción cinematográfica y la imagen de los inmigrantes en la ficción nacional emitida en prime time, tema sobre el que realiza su tesis doctoral. 